\title{
PRODUCTIVIDADES TERAPÉUTICAS: LA POTENCIALIDAD DEL PROCESO CREATIVO
}

\section{Therapeutic productivities: The potential of the creative process learning}

\author{
Laia Manonelles \\ Universidad de Barcelona. Universidad Pompeu Fabra \\ laiam23@hotmail.com
}

Recibido: 12 de junio de 2011

Aprobado: 21 de julio de 2011

\begin{abstract}
Resumen:
Productividades terapéuticas: La potencialidad del proceso creativo parte de la voluntad de aproximarse al trabajo de varios autores que desde diversas disciplinas, como la filosófica, la literaria o bien distintos lenguajes artísticos, experimentan cómo el acto creativo puede devenir terapéutico y subversivo. Bajo tales premisas el arte y la vida se conectan y nutren de manera recíproca. Los autores desarrollan en un primer momento un proceso íntimo, pero siempre con la determinación de realizar una transferencia del cuerpo individual al colectivo. Así pues, las experiencias esbozadas serán un punto de partida para dar forma a un malestar tan individual como sistémico, social.
\end{abstract}

Palabras clave: Arte de acción, arte contemporáneo, arte y procesos terapéuticos

Manonelles Moner, L. 2011: Productividades terapeúticas: La potencialidad del proceso creativo. Arte, Individuo y Sociedad, Vol. 23. Núm. Especial, 181-189

\begin{abstract}
:
Therapeutic productivities: The potential of the creative process departs from the will to come closer the work of several authors who from diverse disciplines, as the philosophical one, literary or different artistic languages, experience how the creative act can develop therapeutic and subversive. Down such premises the art and the life connect and nourish in a reciprocal way. The authors develop in the first moment an intimate process, but always with the determination to realize a transfer of the individual body to the group. This way so, the outlined experiences will be a point of item to give form to a discomfort so individual as systemic, social.
\end{abstract}

Key words: Performance art, contemporary art, art and therapeutic processes 
“A: Escribir es para mí una necesidad-incluso hablando en metáfora me resulta desagradable. B: ¿Entonces por qué escribes? A: Bueno, amigo mío, para serte franco, no he descubierto hasta ahora ningún otro medio de liberarme de mis pensamientos. B: Y, ¿por qué quieres liberarte de ellos? A: ¿Por qué quiero? ¿Acaso quiero? Simplemente, debo hacerlo. B: ¡Basta! ¡Basta! (Nietzsche, 2001: 181).

Nietzsche, en este diálogo de La Gaya Ciencia, introduce la naturaleza terapéutica del acto creativo. En varias de sus obras desarrolla la idea de que la enfermedad puede entenderse como una manera de conocerse y revolver el interior de uno mismo puesto que obliga a vivir en un estado de quietud en el cual se aprende a esperar, a rumiar, y a pensar. El filósofo explica cómo la enfermedad propicia que el individuo se aparte de la masa ajetreada y que, desde cierta distancia, empiece a observarla. Es precisamente entonces cuando aparece una nueva conciencia que le hace entender que su recuperación no consiste en devenir un "ser sedado", un ser pasivo. Pues hay que recordar que Nietzsche sostiene que el sujeto es responsable de su propio sufrimiento y, dentro de tales parámetros, introduce la creación como el mejor antídoto que uno puede ofrecerse a sí mismo. Esta idea queda recogida en varias de sus obras, entre las que cabe destacar especialmente Más allá del bien y del mal, preludio de una filosofía del futuro:

"Crear- esa es la gran redención del sufrimiento, así es como se vuelve ligera la vida. Mas para que el creador exista son necesarios sufrimientos y muchas transformaciones" (Nietzsche, 1972: 133).

La relación del arte con la vida y la potencialidad de la pulsión creativa como un instrumento eficaz para dar forma al malestar serán las premisas en las que profundizará Lou Andreas-Salomé, una pensadora y terapeuta contemporánea a Nietzsche.

Andreas-Salomé se inició en la psicoterapia después de conocer a Freud en el congreso de la Asociación Psicoanalítica Internacional (1911, Weimar) y, a pesar de ejercer profesionalmente el psicoanálisis, advirtió que es mejor no intervenir -cuando el paciente es un artista- al considerar que la propia producción artística es la mejor terapia que éste pueden recibir. Ejemplos concretos de tal parecer se entrevén en las reflexiones que desarrolla a partir de su amistad con Nietzsche. Andreas-Salomé señala el vínculo entre la vida intelectual y la vida psíquica de Nietzsche, quien vivió plenamente su pensamiento, refiriéndose a la bibliografía y a la vida del filósofo como una "historia de dolor" en la que cada período autodestructivo culmina en una renovación y a cada curación le suceden nuevos sufrimientos, fiebres y heridas (Andreas-Salomé, 2005: 73, 87). El dolor deviene un manantial espiritual, y hay que apuntar que su enfermedad se manifestó en los años de mayor productividad. Por ello, tal y como apunta Lou Andreas-Salomé:

"Se vio obligado por su estado de salud a tomarse a sí mismo como la materia de sus pensamientos, a poner su propio yo como fundamento de su imagen del mundo y a tejer ésta desde su propia interioridad" (Ibid.: 147). 
La creación es una vía que ayuda a mediar y expulsar los conflictos. Este es un tema ampliamente desarrollado por muchos filósofos y artistas y, iniciado el siglo $\mathrm{XX}$, otros pensadores - como Jean-Paul Sartre- continúan insistiendo en la responsabilidad del individuo y en la potencialidad del proceso creativo. Justamente, los autores bosquejados en el presente artículo entienden el acto creativo como un instrumento tan eficaz psicológicamente como, a la vez, subversivo.

Sartre en San Genet, Comediante y mártir (1952), el largo prólogo que realizó para las obras completas de Jean Genet, propone una lectura psicoexistencialista de la infancia del escritor, quien después de desertar de la Legión Extranjera (en la cual se había enrolado para salir del correccional para adolescentes donde estaba internado) vagabundeó por Europa robando, prostituyéndose y mendigando. Genet conoció en su propia piel la miseria y fue en la prisión cuando decidió liberarse de su padecer mediante la prosa poética, convirtiendo su creación en una especia de "terapia existencial":

"Su poesía no es un arte literario, es una especie de salud. (...) La poesía no sale de él, ni la dedica a un público: es una manera de vivir" (Sartre, 1952: 337).

El arte se convierte en un mecanismo para procesar, transformar, sosegar y desprenderse del desconsuelo. Sartre analiza detenidamente las tres metamorfosis del joven: en la primera se convierte al Mal, en la segunda se vuelve Esteta, y en la última en Escritor, en Poeta. Genet, en su última conversión, se vuelve hacia los demás para hacerse comprender, para compartir, para aullar, para impactar e increpar a aquellos que reciben sus escritos. El arte parte de la necesidad y es entendido como una salida:

"Infectándonos de su mal, Genet se libera. Cada uno de sus libros es una crisis de posesión catártica, un psicodrama (...). Diez años de literatura le equivalen a una cura psicoanalítica" (Sartre, 1952: 602).

Con Genet queda claro que el arte puede devenir un ejercicio terapéutico y subversivo. Pues tal y como Sartre recalca: "Diez años de literatura le equivalen a una cura psicoanalítica". Además, no se puede obviar que Genet fue un activista, marcadamente comprometido, $\mathrm{y}$ en su producción es preciso subrayar tanto su dimensión individual como la política. El poeta devuelve y enfrenta a la sociedad con aquello que no quiere ver, con aquello que molesta, que produce vergüenza y que permanece escondido, ya sea en cárceles, en barrios marginales o en residencias.

Esta relación entre el sufrimiento personal y el colectivo lo recogió el pensador político Félix Vázquez -en las jornadas "Días de vida y política" (2006) organizadas por el colectivo Espai en Blanc-, en las que se centró especialmente en desmenuzar cómo en la sociedad actual la experiencia de la angustia es individual, desvinculándola del marco político, económico y social. En tal contexto el malestar social se psicomatiza en varias patologías como pueden ser el insomnio, la depresión, el estrés y la ansiedad, y estas manifestaciones de sufrimiento en los individuos que componen la sociedad son monopolizadas por la psicología y la psiquiatría, convirtiéndose en las intérpretes oficiales del malestar. Félix Vázquez recalca que las disciplinas "psi" se han apropiado del dolor, siendo las únicas mediadoras de los estados de depresión 
y angustia, siendo uno de los objetivos controlar y regular la experiencia del sufrimiento.

Bajo esa directriz los sujetos devienen "problemas en sí mismos", incapaces de tomar iniciativas sin el tutelaje de los profesionales, aislándose de la sociedad al concentrar toda la energía en ellos mismos, sin responsabilizarse del padecer del otro, absolutamente ajenos a su mal. Félix Vázquez afirma que el único modo de enfrentarse al sufrimiento es devolverlo a su carácter colectivo, por ello éste no puede ser aislado del marco político y social para intervenir exclusivamente en la subjetividad.

A continuación, para continuar ahondando en cómo la creación se convierte en un medio para encarar -desde otra perspectiva- la angustia y el sufrimiento, se introducirán algunos artistas que comparten la decisión de hacer frente a los conflictos, compartirlos y devolverlos a la sociedad. Lo íntimo se retorna a la esfera pública para propiciar que algo acontezca, para forjar un diálogo, para mostrar la voluntad de expresar, de debatir, de investigar, de reaccionar y, en definitiva, de actuar.

En esta dirección hay que destacar el vídeo del artista Antonio Ortega Aprensión y Esoterismo (2002) [Fig. 1] en el que registra una entrevista a Pere Lluís Plà Buixó. Dicho artista desarrolla un monólogo en el que explica cómo el arte se transforma en su particular terapia contra un mal de hígado provocado por la "mala baba" y por la represión de la sociedad en la que vive. Cito las palabras de Pere Lluís Plà Buixó:

"Pero un exceso de agresividad crea una disfunción, puede crear una disfunción en la que haya demasiada acidosis en el estómago. O bien puede producir, también, un retraimiento de esa acidificación en el sentido de pensar, de tener miedo de que aquel exceso no será bien recibido por lo social, por lo que se reprime, y al ser reprimido es cuando se producen los pólipos y las piedras biliares. Que también se produce en la digestión lenta, al no haber suficiente ácido para producir la digestión" (Ortega, 2003: 187-188).

Pere Lluís Plà Buixó expone, igual que Nietzsche hacía en sus escritos, cómo el sujeto somatiza el malestar transformándolo en problemas digestivos. Y, en consecuencia, propone como remedio a las úlceras de estómago una determinada alimentación, la práctica de la meditación y, sobre todo, la actividad creativa.

Ortega explica que titula esta obra Aprensión y esoterismo porque con el vocablo "aprensión" se refiere a la poca claridad con la que generalmente los expertos transmiten los diagnósticos a los pacientes, y con el término "esoterismo" hace alusión al remedio con el que el artista propone tratar su mal de hígado. Pere Lluís Plà Buixó vomita simbólicamente la "mala bilis" y así evita terminar en un quirófano donde un desconocido proceda a extirparle sus males. Aquí la creación se convierte en una terapia preventiva, tal y como Ortega explica en una entrevista:

"Una de las cosas que él proponía como método fisico - en el que otra persona optaría por la química o bien por la cirugía- era elegir la meditación y la alimentación. Y para evitar el germen de la somatización, que era el "mal rollo", lo corregía con el arte". (Manonelles, 2009: 438) 
Nietzsche y Sartre trata ampliamente el tema de la dispepsia y la náusea y, ciertamente, la sociedad de consumo actual es un vivero de patologías gástricas. Es más; enfermedades como las úlceras de estómago, la bulimia y la anorexia pueden relacionarse con una mala asimilación de la realidad.

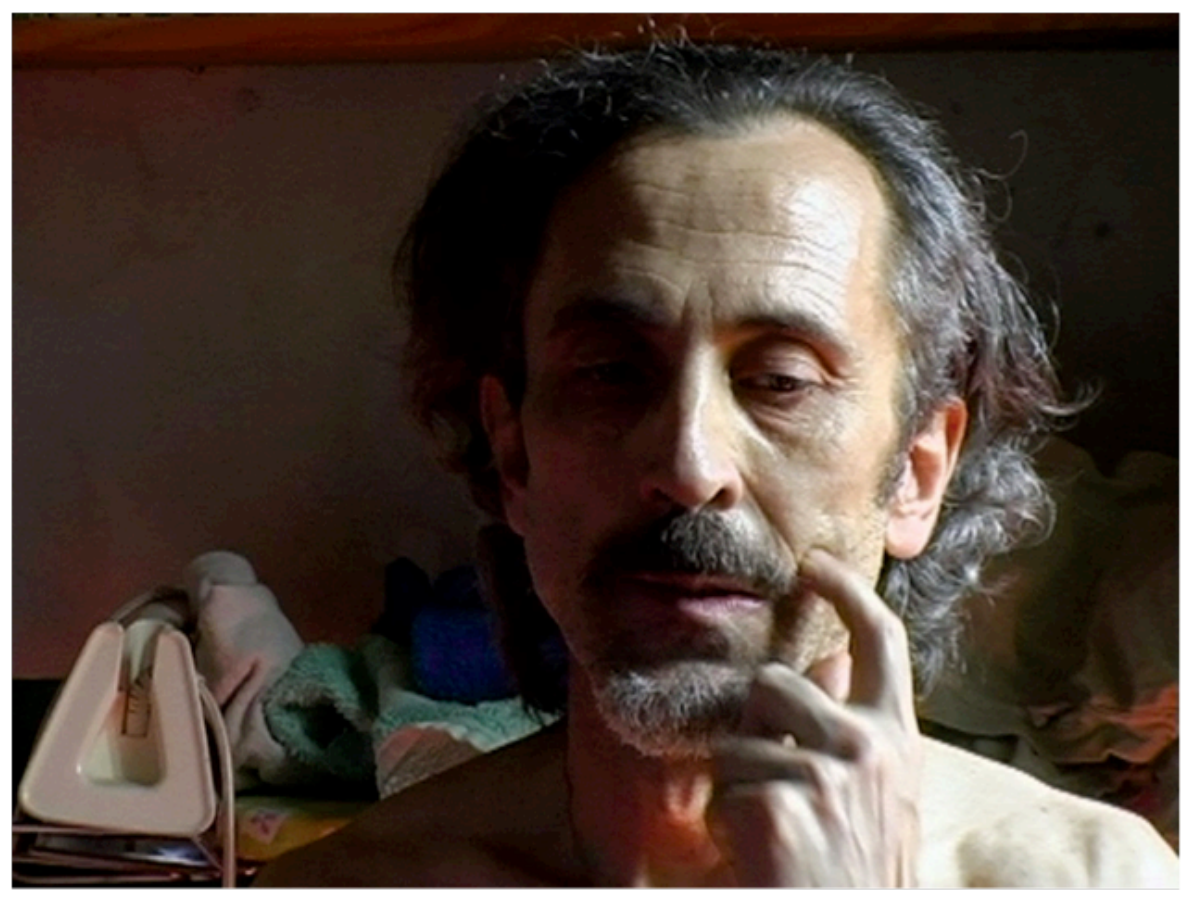

Fig. 1. Antonio Ortega, Aprensión y Esoterismo, 2002.

Otro artista que comparte la misma determinación de afrontar la angustia existencial a partir del proceso creativo es Carlos Pina. Dicho artista reflexiona, desde su propia experiencia, sobre los tratamientos farmacológicos con los que el sistema sanitario trata de aplacar la depresión y la ansiedad. En concreto, en su acción sin público Sindrome de abstinencia (Barcelona, 16 y 17 de septiembre de 2000) manifiesta su voluntad de desafiar su desazón sin la ayuda de psicofármacos. Cito al propio artista:

16 de septiembre. Me despierto pronto, como siempre. Como cada vez que siento malestar en los últimos tiempos me vienen pensamientos de autolesión, como si el malestar pudiera irse sangrando. Me siento irritado y agotado. Pienso en romper un cristal de un puñetazo para que se sepa lo mal que me encuentro. Decido abandonar bruscamente la medicación, consciente de que es solo un gesto para llamar la atención. Paso un día mucho mejor de lo habitual, lo siento como uno de los más felices en mucho tiempo, estoy risueño y alegre, más locuaz, con menos angustia. Sonrío, miro a mi mujer, levanto el puño y le digo: "venceremos". Nos reímos. Salimos. Compro un libro, "El siglo después de Béatrice" de Amin Maalouf. Cenamos fuera. Nos reímos. Tardo mucho en conciliar el sueño, ligero e intermitente. Duermo unas seis horas. 
17 de septiembre. Después del sueño me levanto con mareo leve, que va en aumento. Estoy tumbado en una esterilla. Me duele todo. Sonrio, miro a mi mujer, levanto el puño y le digo: "venceremos". Nos reímos. Empieza el dolor de cabeza y las náuseas. Estoy tumbado en una esterilla. Me duele todo. Sonrío, miro a mi mujer, levanto el puño y le digo: "venceremos". Nos reímos. Ella me mira con preocupación. Vomito una y otra vez, ya no me queda nada por vomitar; tengo descomposición. Estoy tumbado en una esterilla. Me duele todo. Sonrío, miro a mi mujer, levanto el puño y le digo: "venceremos". Nos reímos. Ella me mira con cariño y preocupación. El dolor de cabeza se hace insoportable. Mi mujer llama a la psiquiatra. Ya no estoy siquiera irritado. Estoy tumbado en una esterilla. Me duele todo. Sonrío, miro a mi mujer, levanto el puño y le digo: "venceremos". Nos reímos. Ella me mira con cariño. Me sonríe. Las náuseas remiten, el dolor de cabeza sigue. Estoy tumbado en una esterilla. Ella me mira con amor. Sonrío, la miro, levanto el puño y le digo: "venceremos". Ella sonríe, me mira, levanta el puño y me dice: "venceremos".

El artista relata sus sentimientos y sensaciones y cómo los afronta con un singular mantra que repite junto a su mujer: "Venceremos". Carlos Pina expone claramente el sufrimiento de quien lidia con la angustia sin antidepresivos, a la vez que revela la dependencia a los fármacos y los efectos del fuerte síndrome de abstinencia al interrumpir el tratamiento. Esta acción pertenece a una serie de obras individuales y colectivas, realizadas junto a su esposa y artista Maria Cosmes, dentro del proyecto Salir del armario (F34.1/F60.5).

Carlos Pina y Maria Cosmes crearon el colectivo Stidna! y, partiendo de la misma voluntad de reflexionar tanto sobre la propia ansiedad como sobre los tratamientos recibidos para paliarla y reducirla, propusieron la performance Botiquin (Coslada, mayo 2001) [Fig. 2]. En Botiquín recitaron un largo poema fonético compuesto con los nombres -comerciales y genéricos- de más de una treintena de psicofármacos que Carlos Pina y Maria Cosmes habían consumido durante varios años. Entre otros fármacos citaron nombres tan conocidos como Anafranil, Clomipramina, DiazepanLeo, Diazepam, Dumirox, Fluvoxamina, Lexatin, Bromazepam, Orfidal, Lorazepam, Trankimazin, Alprazolam, Tranxilium, Cloracepato, explicando los propios artistas que el público participó activamente proponiendo y añadiendo los nombres de otros comprimidos.

Con estas performances Carlos Pina y Maria Cosmes muestran cómo el desasosiego es tratado en privado, por el psiquiatra, el psicólogo o el psicoanalista, sin enmarcar la angustia, el estrés o la depresión dentro de una dimensión colectiva. Ambos artistas enlazan el sufrimiento individual con el social lanzando la siguiente pregunta: "Si tantas personas en nuestra sociedad necesitamos esta medicación, ¿quién está enfermo, nosotros o la sociedad?"1

${ }^{1}$ El trabajo del colectivo Stidna! lo analizo con más detenimiento en el artículo: El sufrimiento del sujeto desintoxicado, en la revista La sociedad Terapéutica (2008), y también disponible on-line: http:// www.espaienblanc.net/El-sufrimiento-del-sujeto.html 


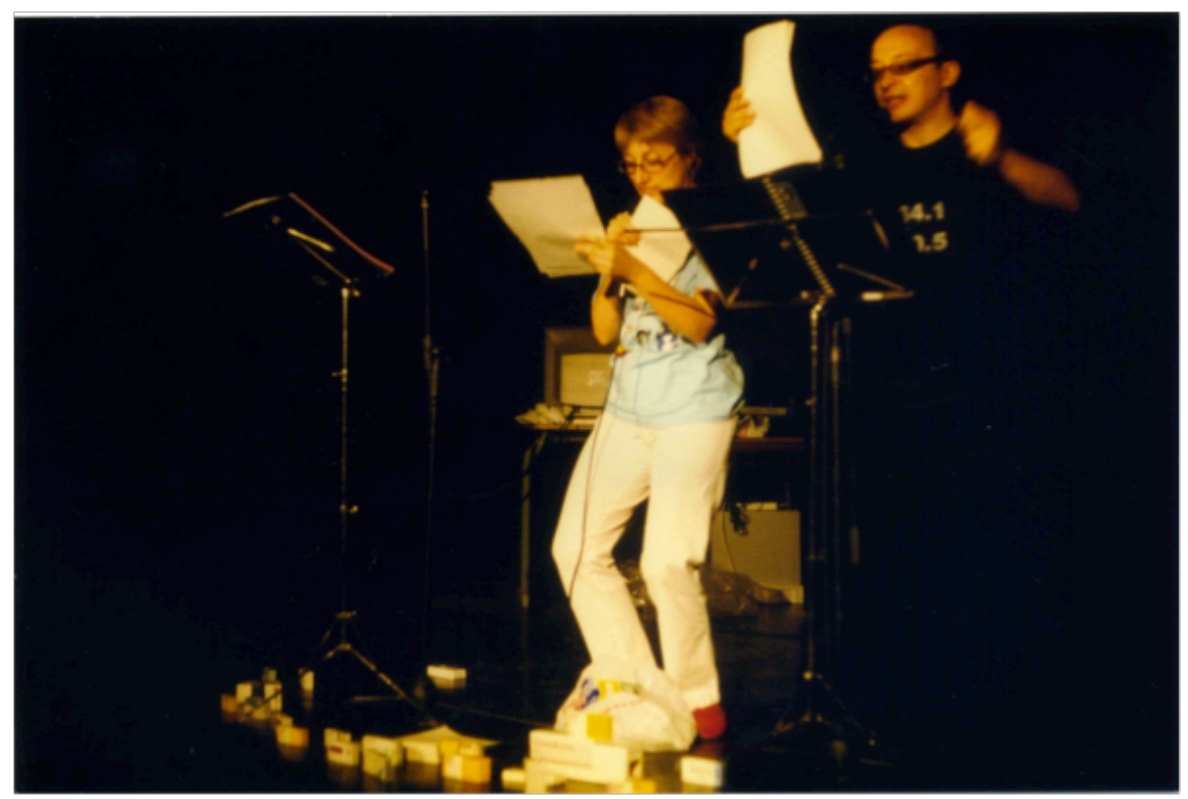

Fig. 2. Carlos Pina y Maria Cosmes, colectivo Stidna! performance Botiquín, 2001

En relación a este tema, en una entrevista realizada a Carlos Pina publicada en el artículo Prospecto: perfiles y experiencias del malestar, dentro de la revista La sociedad Terapéutica, el propio artista matiza la relación entre el malestar sistémico y el individual:

"Personalmente no creo que exista una conciencia generalizada, pues normalmente siempre se consideran las depresiones, las ansiedades y el estrés como temas individuales y no como temas sociales. El tratamiento es personalizado, a todo el mundo nos dan el mismo, pero en teoría en tratamiento es personalizado. No creo que la gente se plantee que sea una cuestión social. Parte del grupo donde estoy tiene unas tareas que son altamente estresantes y van "cayendo como moscas", pero en ningún momento he visto que se hayan planteado que las funciones que tienen sean excesivas o sean estresantes sino más bien se piensa-aunque no se dice-que éste no ha podido aguantar. Los hay que lo aguantan y hay otros que no tienen carácter, que no tienen nervios, que no tienen paciencia para aguantar este ritmo, mientras que otros sí. La gente piensa que es individual, pero yo considero que es totalmente social, porque hay demasiada gente que toma psicofármacos como para que pueda ser una cosa individual. Hay un malestar ligado a cuestiones propias de cada uno y otro vinculado a nuestro entorno social; el malestar que viene de uno mismo se puede resolver con medicación y terapia, pero el que viene de que a uno no le gusta el mundo donde vive dificilmente se lo podrá sacar a no ser que haga él solo la revolución o que arrastre a los demás a hacerla (Manonelles, 2008: 158). ${ }^{2}$

\footnotetext{
${ }^{2}$ Este tema lo analizo con más detenimiento en el artículo Prospecto: perfiles y experiencias del malestar, publicado en la revista La sociedad Terapéutica (2008), y también disponible on-line: http:// www.espaienblanc.net/Prospecto-perfiles-y-experiencias.html.
} 
A partir de los autores expuestos, desde una perspectiva filosófica, poética o recurriendo a diversos lenguajes visuales, queda esbozado cómo la creación -mediante la inducción y la sugestión terapéutica- se convierte en un revulsivo eficaz para tratar los desequilibrios. Pero es preciso ir más allá y constatar que uno de los principales objetivos de tales creadores es compartir y retornar la angustia a la comunidad en la que viven.

Aquí también es necesario apuntar que, en ocasiones, el artista puede transformarse en un intermediario al ofrecer herramientas a sus conciudadanos para lidiar con su angustia. Un ejemplo de ello nos lo brinda el artista coreano Kyungwoo Chun, quien adopta un rol de mediador ayudando a otras personas a expresar metafóricamente su dolor y ejerciendo a la vez de puente entre el malestar individual y social.

En el Centro Huarte de Arte Contemporáneo de Navarra propuso una simbólica acción colectiva "The Weight of Pain" (El peso del dolor, 2008-2009) [Fig. 3], en la cual un millar de personas tenían que escribir su nombre, la fecha y su lugar de nacimiento en la zona exterior de un pañuelo rojo y, en el interior del mismo, podían colocar tantas piedras como fueran necesarias para representar el peso de su dolor, del sufrimiento que soportaban en sus vidas. Y, finalmente, debían atar cuidadosamente las puntas del pañuelo con un nudo central. El Centro Huarte recogió estas experiencias y las reunió en el museo, recordando de esta manera la importancia de amalgamar y crear vasos comunicantes entre los rituales individuales y colectivos.

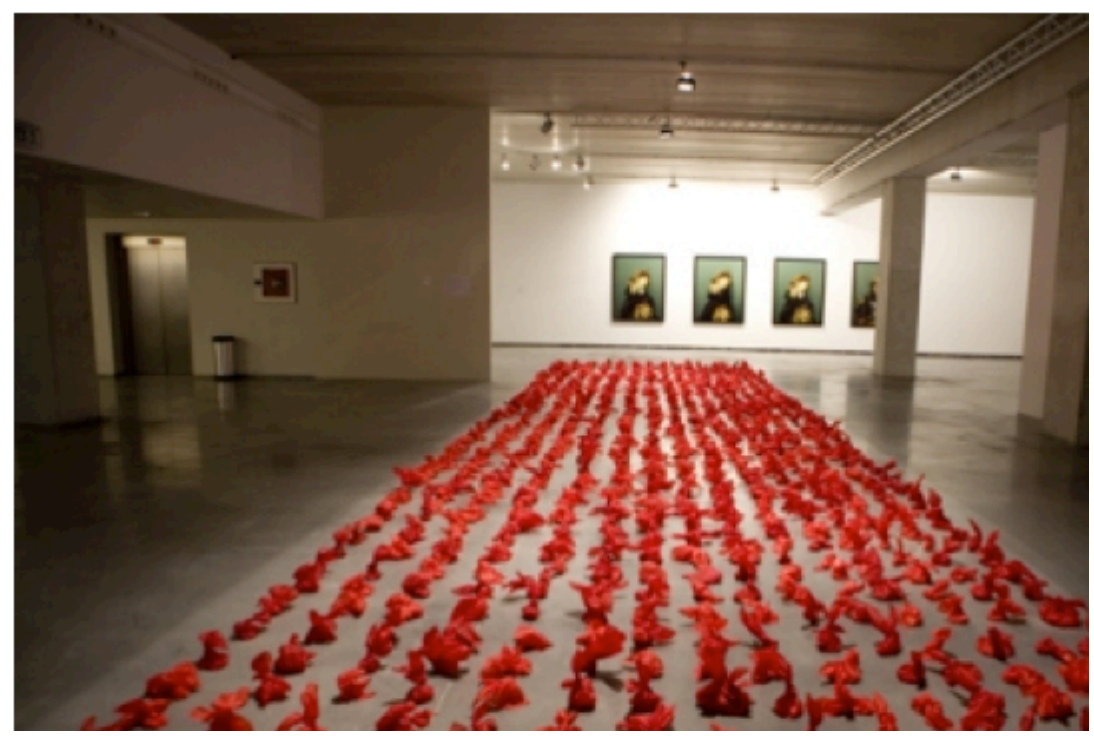

Fig. 3. Kyungwoo Chun, El peso del dolor, 2008-2009. Fotografía de Raul Goñi. ${ }^{3}$

${ }^{3} \mathrm{http}: / /$ www.espaienblanc.net/Prospecto-perfiles-y-experiencias.html 
En esta acción e instalación colaboraron diferentes entidades como el Museo Oteiza, el Colegio Ursulinas, la escuela de Música Joaquín Maya, la Galería Arteko, así como todos los ciudadanos que quisieron sumarse a la iniciativa. Kyungwoo Chun pidió a los participantes una implicación activa y el artista visitó varias de estas instituciones para compartir las reflexiones sobre el proceso de cómo calibrar, fijar y deshacernos del dolor. En esta acción vemos cómo las personas reciben el apoyo de la figura de un artista, aunque la responsabilidad de dar forma a la angustia recae en el propio individuo. El sujeto deja de ser un ente alienado, dependiente y pasivo, puesto que debe participar activamente en la resolución de sus conflictos tomando las riendas, pasando a la acción.

Justamente, tomar la iniciativa es una de las premisas fundamentales de los proyectos que aquí se han introducido. Las propuestas expuestas muestran cómo el arte parte de la necesidad, al fundir la experiencia vital con la artística. El arte se transforma en un remedio que ayuda a modelar, a procesar, a canalizar y a compartir el malestar, remarcando siempre la importancia del proceso, del compromiso.

\section{Referencias}

Andreas-Salomé, L. 2003: Notas de Tautenburg para Lou von Salomé (tr. De José Luis Puertas). Biblioteca nueva, Madrid.

Andreas-Salomé, L. 2005: Friedrich Nietzsche en sus obras (tr. de Luis Fernando Moreno Claros). Minúscula, Barcelona.

AAVV, 2008: La sociedad Terapéutica. Editada por Espai en Blanc y Ediciones Bellaterra. Barcelona.

Manolelles, L. 2009: El arte de acción como terapia y subversión. Peregrinaciones en el arte contemporáneo. Tesis doctoral, Universidad de Barcelona.

Nietzsche, F. 1972: Más allá del bien y del mal, preludio de una filosofia del futuro (tr. de Andrés Sánchez Pascual). Alianza, Madrid.

Nietzsche, F. 2001: La ciencia jovial (tr. de Germán Cano). Biblioteca Nueva, Madrid. Ortega, A. 2000: Figuraciones, arte civil, magicismos, espacios de frontera. Caja Madrid, Barcelona.

Rilke, R.M. Andreas-Salomé, L.1981: Correspondencia (tr. de Jose Ma. Fouce Fernández). Hesperns, Barcelona.

Sartre, J. P. 1952: Saint Genet, comédien et martyr. Gallimard, Paris.

Sartre, J. P. 2002: La náusea (tr. de Aurora Bernárdez). El País, Madrid.

WEB:

Espai en Blanc: http://blog.sindominio.net/blog/espai_en_blanc

Manoelles, L: http://www.espaienblanc.net/El-sufrimiento-del-sujeto.html http://www.espaienblanc.net/Prospecto-perfiles-y-experiencias.html

Ortega, A: http://www.antoniaortega.com/. [Última consulta: 20 de mayo de 2008].

Pina, C: http://www.stidna.org/performance/home.htm

Kyungwoo Chun: http://www.centrohuarte.es/index.php/es/actualidad/noticias/milpersonas-intervendran-en-la-instalacion-el-peso-del-dolor-en-el-centro-huart 